\section{Smart textiles respond to human emotions}

\author{
By Tal Fox
}

$\mathrm{N}_{\mathrm{b}}^{\mathrm{o}}$ owadays, as wearable technology becomes an ever-growing phenomenon, you can monitor your daily activity with a flick of the wrist. Felecia Davis, associate professor at the Stuckeman Center for Design and Computation at The Pennsylvania State University (Penn State), wants to take this a step further as she explores how our day-to-day interactions with textiles can be used to alter our relationship with our surroundings.

"I'm trained as an architect and I like to look at how we might use textiles that have electronic sensors embedded into them that [can be programmed] to have different responses to their environment so they can communicate different responses," says Davis.

Communication, which takes form through all five senses, plays a significant role in our daily lives and how we respond to our environment. However, for some individuals, a struggle with communication, whether that includes being able to convey their emotions or even being able to distinguish them, can prove to be problematic.

In 2012, Davis collaborated with a research team at Microsoft Research to create a prototype wall panel of fabric, referred to as a Textile Mirror, which helps break down barriers for people who need to learn how to identify and express their emotions.

The idea was inspired by J.G. Ballard's short story, "The Thousand Dreams of Stellavista," which tells the tale of a house that could read its inhabitants' emotions and reflect them through its appearance. Davis scaled back this idea by creating a panel that uses sensors for the same purpose.

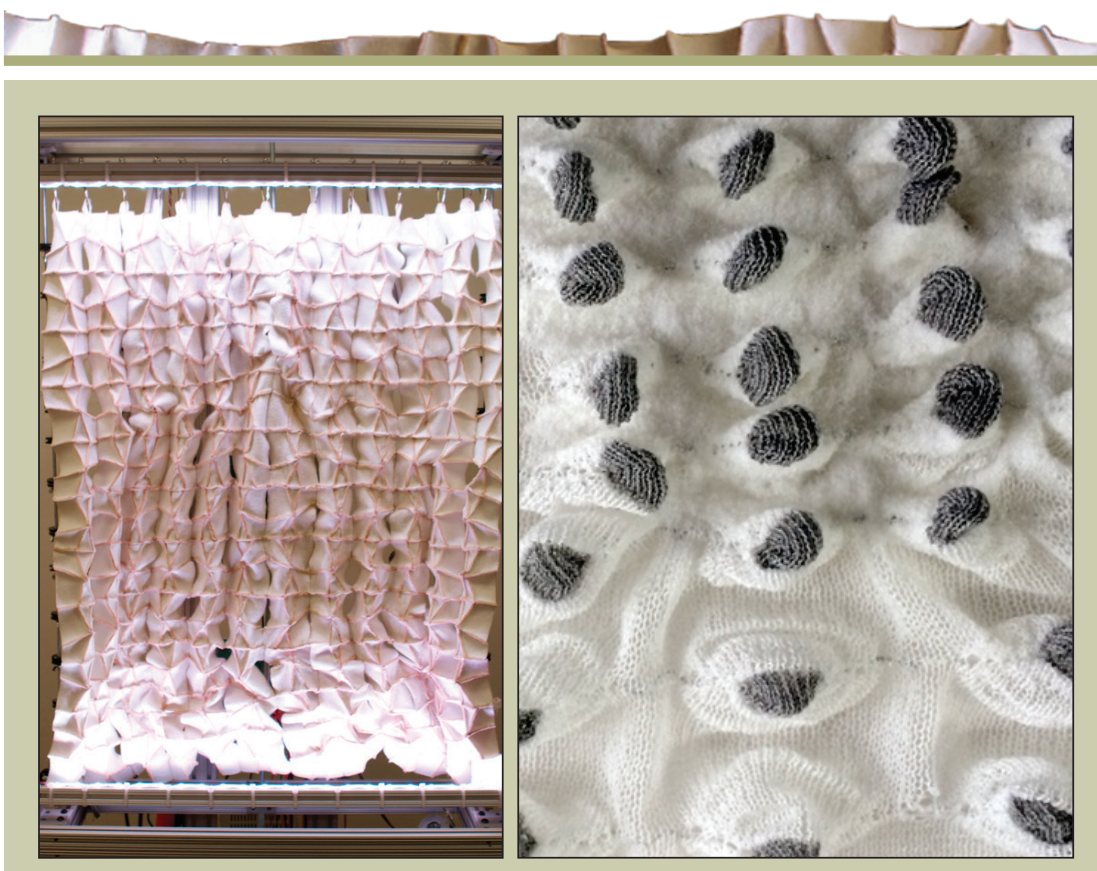

(Left) The Textile Mirror is a prototype wall panel that changes shape in response to people's emotions. () 2020 Microsoft Research. (Right) A sample using resistive yarns that can be used as a sensor. () Felecia Davis.

She was also influenced by her advisor, Leah Buechley at the High-Low Tech Laboratory at the Massachusetts Institute of Technology Media Laboratory. The unique features in the laboratory include a pink wall with flowers connected by vines and painted with conductive paint as well as another wall holding wearable sensors.

"That was one of my most exciting moments during my $\mathrm{PhD}$ just to see her lab and hearing how one could learn about computer science in a way that was totally aesthetically pleasurable and engaged all the different senses," Davis says.

The design studio where Davis works today, SOFTLAB, combines fabrics with electronics and sensors, sending signals to the textile to respond. The Textile Mirror prototype is a mediator that communicates emotion back to the individual. Imagine coming home after witnessing a rather upsetting event, and as you walk through the front door, the wall crumples up into a tight pattern reflecting your distress, anger, or anxiety.

"We made a textile that crumpled up and we called it its 'angry state,' and when it smoothed out we called it its 'calm state,", Davis says.

"Some people don't really know when they're upset, depressed, or angry. Maybe we can put sensors on that person and have a reading go to a textile to make them aware of what's going on in their bodies instead of biting your nails or ripping your hair out," Davis explains.

The mirror is made up of 80 pieces of laser-cut felt and fused together with Nitinol wire and contains a series of motors permitting movement. Nitinol is a superelastic alloy, made up of nickel and titanium, well known for displaying a shape-memory effect and "remembering" its original state. The signal-whether that be from a household textile, item of clothing, or a smartphone - then stimulates the object, causing the encased Nitinol wire to contract and thus the fabric to fold.

The felt absorbs a lot of the heat from the Nitinol, which makes the fabric fold up along accordion pleats, but the metal got too hot to touch. Wool proved to be the optimum fabric to use as it was the 
least flammable option. Once the Nitinol wires slowly cooled down, they would straighten back out; however, this could be a lengthy process. In order to speed it up, extra weights were placed at the ends of the wires.

The mirror prototype is connected to a smartphone that communicates an emotional reading to the textile, allowing it to change form. However, this required the user to input their emotion that would feed back to the textile. Rather than having the user select the emotion, the research team decided to use heart sensors and galvanic skin sensors to detect changes in heart rate, pulse, sweat, and breathing. The sensors were attached to items of clothing worn close to the body such as leggings, because good contact with the skin and body was vital for the reading.

The team wanted to create a textile that could read its environment and learn from it in order to understand a change in a person's emotional responses without the individual having to create the prompt.

The warmth from the wire provided comfort to those who touched it and the researchers found that engaging a sense of touch impacted the way people responded to the textile as well. Naturally, it was also important that the textile suit the application, whether that be a wall panel, pillow, or even a chair.

"I think this can be used for people who have trouble communicating verbally. It may help people unlock what they're feeling and feel more comfortable and connected to the world if they're able to feel things and touch things, in addition to communicating verbally," Davis says.

A follow-up study called "FELT" helped the team at SOFTLAB refine the preliminary study by exploring animal reactions and looking at ways of mirroring them. For example, a cat might arch its back to communicate when it is frightened. In a similar fashion, the textiles might reflect these movements to express the same emotion. The sensors in the panel could then detect how a person is feeling and echo it to alert someone who may otherwise be unaware. The next step would be to incorporate touch to help alter their state to something more positive.

While understanding how touch and vision work together when communicating emotions, Davis discovered that memories play a significant role in how people respond to different situations. People were more engaged with the textiles if they could relate it to something familiar, for example the comfort of a soft toy. The memory would then change the

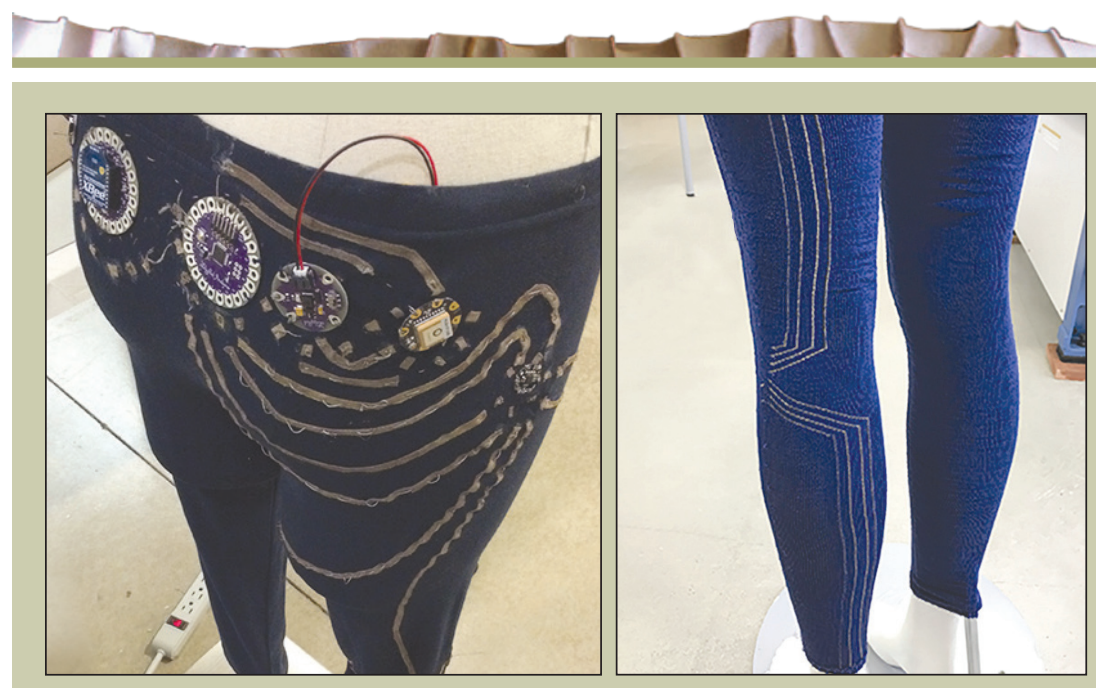

The leggings are made from PA/Lycra knitted fabric that allows it to fit tightly to the body. The circuits are knitted with highly conductive yarn (staten shieldtex 117/17) to connect the external sensors placed on the garment. The quantified walk prototype was manufactured at the Swedish School of Textiles, Delia Dumitrescu and Kristian Rödby 2017. Team: Felecia Davis, Delia Dumitrescu, Kristian Rödby. (c) 2020 Felecia Davis.

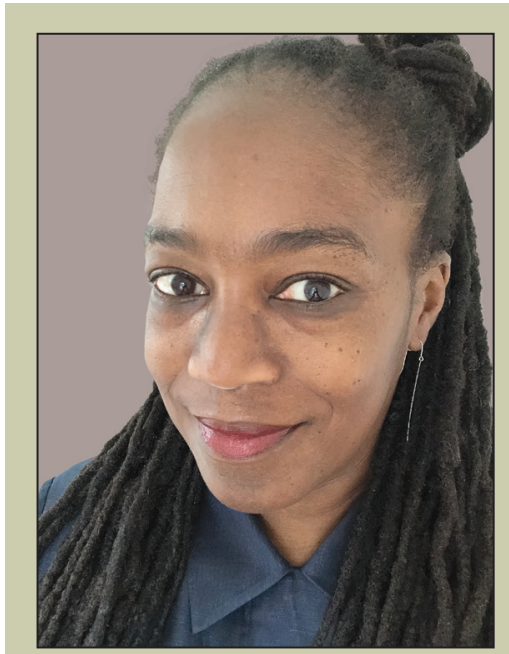

Felecia Davis, Associate Professor at the Stuckeman Center for Design Computing in the School of Architecture and Landscape Architecture at The Pennsylvania State University and director of SOFTLAB@PSU, designs smart textiles that respond to human emotion. Credit: Felecia Davis.

way they interacted with the textile and the way it would respond to them, too.

Being an architect helps Davis understand the importance of aesthetics alongside the scientific elements. However, an additional angle that had to be implemented, she says, is the complexity of psychology and how people respond in a different environment from the one to which they are accustomed. Experiments provided a solid baseline but a controlled environment does not reflect authentic human experience.

Davis says, "I am a designer and when you get into psychology, you need the help of psychologists, but even psychologists have the same problems: The minute you put people into a scientific background, it changes everything."

In order for a person to connect to a textile, it has to appear attractive to the user, so creating something aesthetically pleasing is important for engagement. Unless, of course, you wanted to use the textile as a warning and then something repellent would be more apt.

When we picture robots, we are likely to picture emotionless metal frames. However, Davis's vision for these robotic textiles is to take the form of something familiar or comfortable for the consumer. 


\section{featuRes beyond the lab}

"You could make a stuffed animal, a chair, or a dress," Davis says. "Using the same textile in three different examples changes what gets communicated from it and what messages are sent from the textile to other people."

"Aesthetics plays a huge role because if things are repellent, people don't want to deal with them. If people see something that they don't want to touch or they don't want to engage with down the whole list of senses, then they're not going to connect," she says.

While the Textile Mirror is a prototype, Davis can see the science being applied to objects we already use in our everyday lives. According to Davis, such products could be out in the real world already if she didn't have one major concern. While the data collected by these textiles could have some very beneficial uses across multiple industries, her concern is how data protection policies will affect the users; that is, who might be holding the data and how might they use them.

For example, if a clothes shop started producing clothing with sensors in them, the shops would suddenly have all these data on their customers. It raises the question whether they should be able to hold onto data like these.

Davis says, "It's important for science to pause and go, 'What's the impact we're trying to do here? What do we think are positive directions for human life?'”

Before bringing any items into the marketplace, Davis wants to be sure that these textiles will have a positive impact on people and their environment.

"The next steps are to spend time thinking about what are some ways one can bring this technology to the public and shape the policies ... in our country," she says.
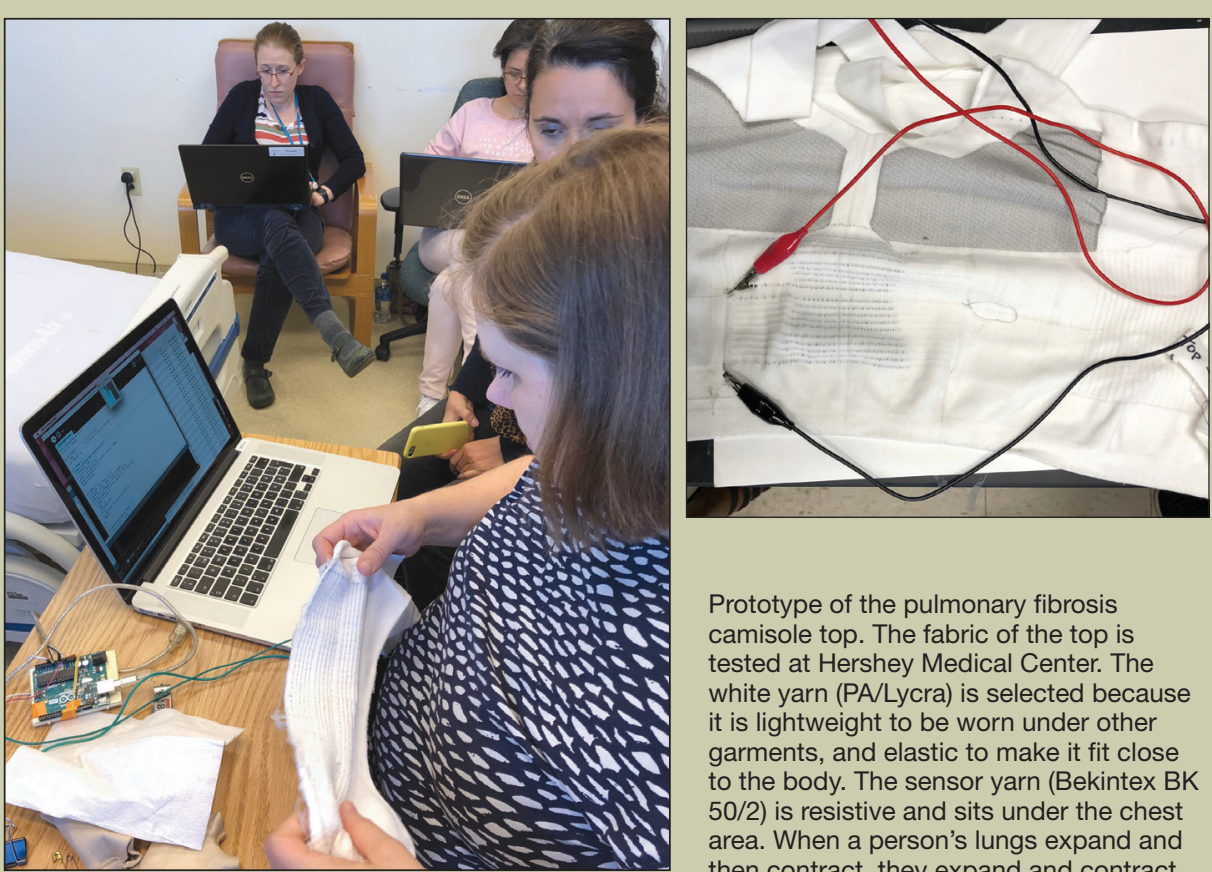

Prototype of the pulmonary fibrosis camisole top. The fabric of the top is tested at Hershey Medical Center. The white yarn (PA/Lycra) is selected because it is lightweight to be worn under other garments, and elastic to make it fit close to the body. The sensor yarn (Bekintex BK $50 / 2$ ) is resistive and sits under the chest area. When a person's lungs expand and then contract, they expand and contract the resistive yarn that is connected to a microcontroller that can read the patterns of coughing. For stitching, lace structures are chosen for the sides and back to allow a better thermal circulation, and full rib on the front side for more elasticity and better ability to stretch and recover the original shape. The Team who made the top: Rebecca Bascom, MD, PSU Hershey College; Felecia Davis; and Dr. Dumitrescu of the Swedish School of Textiles. Seen in photo (top left): Erin Lewis, 3rd year PhD student, Swedish School of Textiles (front); then Delia Dumitrescu; Anne Dimmock, 1st year Hershey Medical student (back left); and Farzaneh Oghazian, 3rd year PhD student, Penn State University, SOFTLAB in the Stuckeman Center for Design Computing. Image credit: Delia Dumitrescu at the Swedish School of Textiles (C) 2020; Image credit, top right and bottom left: Felecia Davis () 2020.
As well as enhancing emotional needs, Davis has been looking at ways to implement these textiles in the medical world. She has been exploring ways to help patients get up and move about rather than be confined to a hospital for tests. For example, she worked on leggings that have sensors linked to the hips, knees, and ankles, which would help identify those with Parkinson's disease.

She started her own firm to combine the academic and practitioner world so that together they can revolutionize the way they can help people in the future. "I think the design world is a funny place because it's neither science nor a pure art but you need both to be able to succeed at what you're doing," Davis says. "You need sociology and psychology and you need to think about all these other things that allow us to be in the world to allow people to achieve their best potential."

We welcome comments and feedback on this article via email to Bulletin@mrs.org. 